\title{
Crossing Borders. A Filosofia da Identidade e a Transculturalidade na Arte CONTEMPORÂNEA Africana ${ }^{1}$
}

\author{
Marita Rainsborough ${ }^{2}$
}

RESUMO: No centro da filosofia de Kwame A. Appiah encontra-se a questão da identidade. Partindo do conceito da liberdade de Mill, ele considera a criação de uma identidade pessoal, no sentido de individualidade particular, uma tarefa permanente - como projeto individual. Nesse contexto, os planos de vida não devem ser concebidos como genericamente rigorosos, mas sim incoerentes e muitas vezes mutantes. Com isso, a identidade não se deve entender como algo fixo e cerrado, porém, como uma espécie de mosaico de vários elementos que se encontram em reprogramação contínua - como formação híbrida. A construção da identidade encerra a narração de histórias de vida, tanto individual como coletiva. Os respectivos elementos podem recorrer a diferentes experiências transculturais, consoante a história coletiva e a história de vida do indivíduo. Assim, a transculturalidade é importante, não só para identidades coletivas, como também sempre em nível de identidade pessoal. O filósofo africano Achille Mbembe alude ao nomadismo do ser humano e à imersão e dispersão culturais associadas que se deixam ler como processos da transculturalidade. Na arte africana contemporânea, esses processos da formação da identidade refletem-se no transcultural. Como exemplos, devem ser apresentados os artistas Edson Chagas, Kehinde Wiley, Yinka Shonibare e Romuald Hazoumè, com obras selecionadas.

PALAVRAS-CHAVE: Identidade pessoal e coletiva. Transculturalidade. Arte africana contemporânea. Diáspora africana. The culture game.

\section{INTRODUÇÃo}

No centro da filosofia de Kwame Appiah encontra-se a questão da identidade. Partindo do conceito da liberdade de Mill, ele considera a criação de uma identidade pessoal, no sentido de individualidade particular, uma

\footnotetext{
${ }^{1}$ http://dx.doi.org/10.1590/S0101-31732016000500009

${ }^{2}$ Docente no Instituto de Letras Românicas da Universidade Christian Albrecht de Kiel, faz PósDoutorado, atualmente, na Universidade de Hamburgo. Suas áreas de trabalho são, principalmente, filosofia do sujeito, filosofia das emoçôes, filosofia da cultura, filosofia da história, cosmopolitismo, filosofia intercultural e estética. É autora da Dissertação intitulada Die Konstitution des Subjekts in den Romanen von Rachel de Queiroz. Eine diskursanalytische Untersuchung, Frankfurt am Main, 2014. Além disso, publicou ensaios sobre Foucault, Kant, o cosmopolitismo e a emotividade na literatura e no cinema. marita.rainsborough@uni-hamburg.de
} 
tarefa permanente - como projeto individual. Nesse contexto, os planos de vida não devem ser concebidos como genericamente rigorosos, mas sim incoerentes e muitas vezes mutantes. Com isso, a identidade não se deve entender como algo fixo e cerrado, porém, como uma espécie de mosaico de vários elementos que se encontram em reprogramação contínua - como formação híbrida. A construção da identidade encerra a narração de histórias de vida, tanto individual como coletiva. Dos momentos da construção de identidade fazem parte categorias como raça, gênero, nação e tribo, que, segundo Appiah, se baseiam em ficçôes. Os respectivos elementos podem recorrer a diferentes experiências transculturais, consoante a história coletiva e a história de vida do indivíduo. Assim, a transculturalidade é importante não só para identidades coletivas, como também sempre em nível de identidade pessoal. O filósofo africano Achille Mbembe alude ao nomadismo do ser humano e à imersão e dispersão culturais associadas que se deixam ler como processos da transculturalidade. $\mathrm{Na}$ arte africana contemporânea, esses processos da formação da identidade refletem-se no transcultural. Como exemplos, devem ser apresentados artistas como Edson Chagas, Kehinde Wiley, Yinka Shonibare e Romuald Hazoumè, com obras selecionadas. Como se refletem esses processos da formação da identidade no transcultural, na arte africana contemporânea? É viável, numa situação pós-colonial, recorrerse ao autóctone da arte africana? Pode-se deduzir das peças da arte que estas assentam numa concepçáo de interculturalidade ou de transculturalidade? Que forma especial da estética do entremeio é reproduzida nas obras de arte?

\section{Identidade e Transculturalidade. Contemplaçóes Filosóficas}

Appiah assume o conceito de Mill de um plano individual de vida como parte de uma realização individual. "He who chooses his plan for himself, employs all his faculties”. (MILL apud APPIAH, 2007a, p. 5). ${ }^{3}$ Appiah parte, nesse contexto, de uma responsabilidade própria do indivíduo com respeito à sua formação de vida. Seu pensamento tem por base um conceito liberal de eleição individual, auto-observação, autocontrole, capacidade de decisão e ponderação, de preferência no sentido da imagem do homem do liberalismo. Ele parte da concentração e da perseverança no objetivo e do desejo do desenvolvimento ulterior das capacidades próprias no pensamento e na atuação humanos. No entanto, esses momentos não devem ser interpretados

${ }^{3}$ MILL em APPIAH, Kwame A. The Ethics of Identity. Princeton: Princeton University Press, 2007a, p. 5; aqui, Appiah cita On Liberty, de Mill. 
como processos exclusivamente racionais, porque também encerram elementos emocionais e sociais. As identidades são construídas narrativamente:

Every human identity is constructed, historical; every one has its share of false presuppositions, of the errors and inaccuracies that courtesy calls "myth", "religion" "heresy", and "science" "magic". Invented histories, invented biologies, invented cultural affinities come with every identity; each is a kind of role that has to be scripted, structured by conventions of narrative.(APPIAH, 2001, p. 373).

Appiah trata particularmente os conceitos de "raça", "tribo" e "nação". As construçôes de identidade recorrem a essas categorias que, por sua vez, devem ser vistas como construídas. Ele nega especialmente a opinião de que a raça é biologicamente fundada e sustenta que essa ideia não é cientificamente correta. "In short, I think it is clear enough that a biologically rooted conception of race is both dangerous in practice and misleading in theory: African unity, African identity, need securer foundations than race". (APPIAH, 2001, p. 375). Destaca que um conceito biológico de raça documenta um pensamento retrogressivo. ${ }^{5} \mathrm{O}$ conceito filosófico de identidade de Appiah contém uma transcriçáo creativa permanente dos momentos que a constituem na sua hibrididade e uma mudança na composição e atribuição da importância dos respectivos elementos, no processo narrativo da formação de identidade, em termos de lembrança e esquecimento nos processos sócio-históricos. As experiências de diferença de encontros interculturais são aceitas de uma maneira especial, pelo que se constata uma correlação teórica entre formaçáo de identidade e transculturalidade. $\mathrm{O}$ encontro de culturas diferentes devido à migração, exílio e diáspora forçados e a formas voluntárias, tais como migração de trabalho e viagens, está unido, segundo Achille Mbembe, à criação de identidades híbridas que, em parte, estão vinculadas a experiências traumáticas. Assinala que a África sempre fora um lugar de imersão e dispersão e que a mobilidade, particularmente o deslocamento de refugiados e a migraçáo de trabalho, determinava também a forma de viver atual. Mbembe se refere a um “[...] paradigme de l'itinérance, de la mobilité e du déplacement". (MBEMBE, 2005). Também para Appiah, a mobilidade do homem é relevante no contexto

\footnotetext{
${ }^{4}$ Appiah critica, entre outros, Du Bois, porque salienta que, por trás do seu conceito sócio-histórico de raça se ocultava um viés biológico. "The truth is that there are no races", constata Appiah. In: APPIAH, Kwame A. The Illusions of Race. Em: EZE, Emmanuel C. (Ed.). African Philosophy: An Anthology. Malden, Oxford, Carlton: Blackwell, 1998, p. 287.
}

5 “[A] racialized conception of one's identity is retrogressive". (APPIAH, 2001, p. 380). 
das formaçôes de identidade. De acordo com ele, o homem é uma espécie migratória:: "The urge to migrate is no less "natural" than the urge to settle". (APPIAH, 2007b, p. xvi) A mobilidade apresenta-se, pois, como fator decisivo para a construção de identidades interculturais e transculturais.

O conceito de transculturalidade, cujo representante mais importante é Wolfgang Welsch, (2012) é compreendido como crítica ao modelo da interculturalidade. Não se trata de um conceito de culturas fechadas em si; Welsch acentua o caráter basicamente híbrido da cultura, o qual tem por base processos de intercâmbio culturais, possibilidades mútuas de adesão e a formação de formas misturadas e novas, da criação de uma nova cultura híbrida. Os termos intercâmbio, fusão, combinação, inbetween, hibrididade e crioulização tentam formular esse processo, terminologicamente. No foco da contemplação estão objetos, símbolos, imagens e ideias transculturais e a análise de interconexóes de artefatos transnacionais, sistemas de símbolos e práticas, não a compreensibilidade e a identificação de culturas de partida supostamente autênticas. $\mathrm{O}$ ponto de partida é o conceito de processos de construção permanentes, dinâmicos e recíprocos. Contudo, nesse modelo, não se descarta completamente a opiniáo de culturas de partida. "A ligação do prefixo "trans" com os termos constituintes de comunidades tais como nação, cultura e Estado deixa concluir tanto uma suspensão de demarcações como também uma reassociação aos mesmos". (HÜHN et al., 2010, p. 15) ${ }^{7}$. Esse processo de reassociação remete para situaçôes de partida culturais, mas que já devem ser sempre vistas como híbridas e processuais. Nesse modelo da transculturalidade, a ideia do regresso a culturas

\footnotetext{
6 "And the way of segragation and seclusion has always been anomalous in our perpetually voyaging species. Cosmopolitanism isn't hard work; repudiating it is". (APPIAH, 2007b, p. XVIII).

${ }^{7}$ HÜHN, Melanie; LERP, Dörte; PETZOLD, Knut; STOCK, Miriam (Ed.). Transkulturalität, Transnationalität, Transstaatlichkeit, Translokalität: Theoretische und empirische Begriffsbestimmungen. Münster, Berlin, London: LIT, 2010, p. 15. Essa tradução da citação do alemão para o português, como também as seguintes citaçôes, foram feitas por Susanne Mahling-Schrader. Com respeito à importância do prefixo "trans", lê-se em Elberfeld: "Os significados básicos em latim são "além de", "através", "para trás”, "para além de”. Segundo estes significados "transcultural' pode significar - seja na versấo alemã, inglesa ou francesa - "para além do cultural", "através de todo o cultural no sentido de por todo o cultural" ou "para além do cultural no sentido de acima do cultural". Ao contrário dos outros dois prefixos "inter" e "multi", que têm um significado pluralístico [...], o prefixo "trans" no adjetivo mencionado refere-se a uma dimensão uniforme que não é ultrapassada nem penetrada. $\mathrm{Na}$ forma substantivada ultimamente surgida, o termo é "transculturalidade". Em: ELBERFELD, Rolf. Forschungsperspektive "Interkulturalität": Transformationen der Wissensordnungen in Europa. Em: KONERSMANN, Ralf; KROIS, John M.; WESTERKAMP, Dirk (Ed.). Zeitschrift für Kulturphilosophie. Bd. 2/1, 2008. p. 20f. O termo exprime um estado. Segundo Elberfeld, a escolha do termo foi motivada possivelmente pelo relativismo cultural da etnologia nos anos 70. (Comp. ELBERFELD, 2008, p. 21).
} 
originais autênticas não é integrável, o que é exigido repetidamente por vertentes tais como, entre outras, o panafricanismo e o movimento de negritude, por exemplo, em termos de recurso a ritos tradicionais, línguas africanas e religióes tradicionais. Um tal recurso ao autêntico só é teoricamente compreensível como processo da construção de tradição e autenticidade. ${ }^{8}$ Por isso, para essas formas construídas de uma suposta autenticidade só é possível recorrer ao Memorial, ou seja, ao arquivo cultural acumulado.

Segundo Dhouib, a transculturalidade também vai mais além da interculturalidade, uma vez que nesse princípio se tenta encontrar normas e valores comuns e fundamentá-las como universais de uma certa forma novamente compreendida. ${ }^{9}$ Ele assevera: "O conceito da interculturalidade vai mais além do pluralismo fático das culturas, reconhecendo e reconstruindo o que une os homens, para conservar a unidade do humano. Baseada, nisto, a tranculturalidade tenta pensar a universalidade das normas como princípio comum e aspirar uma atuação correspondente." (DHOUIB 2011, p. 292) (D) $^{10}$ A teoria de Bhabha do third space (RUTHERFORD, 1990), que acentua o

\footnotetext{
${ }^{8}$ Sobre essa temática, ver também HOBSBAWM, Eric; RANGER, Terence (Ed.). The Invention of Tradition. Cambridge: Cambridge University Press, 2015. Os autores analisam primariamente a invenção de tradiçôes em contextos nacionais. Aqui, a tese compreende-se de modo mais generalizado: trata-se tanto do processo da construção de tradiçốes na reiteração, como também da recriação criativa; eventualmente, de elementos já existentes.

${ }^{9}$ Com isso, recorre à importância tradicional do termo "transcultural". (Comp. ELBERFELD, 2008). É precisamente esse componente de importância por que Elberfeld prefere o termo "intercultural”, ou seja, "interculturalidade", em vez do termo "transcultural", isto é, "transculturalidade". "São sobretudo os diferentes significados do prefixo "inter" que sugerem preferir a palavra "interculturalidade", para denominar uma perspetiva de transformaçáo detalhada, em vez da palavra "transculturalidade" [...], que sobretudo na forma de adjetivo possui uma tonalidade muito universalista". (ELBERFELD, 2008, p. 25). Conforme Dhouib, no conceito de interculturalidade já se procura o que une as diferentes culturas, o que une os homens no mundo. A transculturalidade formula, partindo disso e para além disso, normas universais obrigatórias como base da atuação humana. Essa fixação do objetivo é rejeitada por Elberfeld.

${ }^{10}$ DHOUIB, Sarhan. Zur Transkulturalität der Menschenrechte. Em: DHOUIB, Sarhan; JÜRGENS, Andreas (Ed.). Wege in der Philosophie: Geschichte - Wissen - Recht - Transkulturalität. Weilerswist: Velbrück Wissenschaft, 2011. p. 292; nessa perspectiva, cita também Fathi Triki: "a transculturalidade [utiliza] novamente o aspeto crítico de todas as culturas para determinar, simultaneamente, de modo transversal e transcendente o que poderia ser universal e criar assim um corpo crítico e valores comuns permanentemente renováveis, que devem valer a humanidade". Ver: TRIKI, Fathi. Pluralisme culturel et transculturalité. Em: KÜHNHARDT, Ludger; TAKAYAMA, Mamoru (Ed.). Menschenrechte, Kulturen und Gewalt. Ansätze einer interkulturellen Ethik. Baaden-Baaden: Nomos, 2005, p. 336. Segundo Triki, as culturas são unidas por um movimento transversal atravessador que contém uniôes ontológicas e históricas. Partindo disso, ele exige uma transcrição da história que contenha uma teoria transcultural da era moderna e que integre a filosofia árabe dos séculos XII e XIX. Comp. TRIKI, Fathi. Die Transkulturalität der Philosophie: Die Philosophie des Mittelmeerraums. Em: DHOUIB, Sarhan;
} 
diferente e discrepante no inbetween, apresenta semelhanças com o conceito da transculturalidade, todavia, renuncia ao aspeto da busca de normas e valores obrigatórios para todos, no sentido de um universalismo parcial, cuja existência é pressuposta também por Appiah como uma espécie de consenso mínimo de todos os seres humanos. O objetivo comum é uma convivência humana entre os seres humanos das diferentes culturas, as quais se encontram num processo de transformaçáo permanente. Nesse contexto, a interculturalidade e a transculturalidade devem ser pensadas em uniáo; processos transculturais assentam em processos interculturais. (DHOUIB, 2011, p. 293). Nota-se claramente a tentativa de ir além do intercâmbio, da justaposição e da crítica recíproca das culturas, e de perseverar um núcleo obrigatório na busca do comum que possa perdurar num novo humanismo, numa nova concepção de moralidade, ${ }^{11}$ num universalismo ético novamente concebido, ${ }^{12}$ na questão da orientação e estrutura políticas e numa meta comum, entre outros, por exemplo, em forma de cosmopolitanismo parcial ou de afropolitanismo, como em Appiah e Mbembe. Nesse sentido, coloca-se a questão da identidade africana em termos pessoais, éticos, nacionais e panafricanos em relaçáo à crescente globalização mundial. No âmbito da arte africana, essa matéria é visualizada e refletida particularmente com o tema "máscara e retrato", nas diferentes mídias, ou seja, fotografia, pintura, cinematografia e arte de objetos.

\title{
2 Reflexóes Teóricas Culturais com Respeito à Máscara, ao Retrato e Ao Rosto
}

Lema:

\begin{abstract}
"African art and African contemporary art, actually when two words are said, African art is being said naivly or stupidly, the first thing that comes to my mind is, oh my god, they gonna show me about the mask again which I have seen a billion times. And you know - I know it all - Lord help my soul. So whenever someone says African art, I am already looking towards the sky, thinking show me something new apart from the mask please - please don't show me the mask again. (ADEBESIN 2009, p. V.I.7)”13
\end{abstract}

JÜRGENS, Andreas (Ed.). Wege in der Philosophie: Geschichte - Wissen - Recht - Transkulturalität. Weilerswist: Velbrück Wissenschaft, 2011. p. 358-369.

${ }^{11}$ Fathi Triki, por exemplo, alude a uma "ética da convivência". (TRIKI, 2011, p. 368).

${ }^{12}$ Triki defende, semelhantemente a outros filósofos, um humanismo crítico e um universalismo dividido. (Comp. TRIKI, 2011, p. 367).

${ }^{13}$ KROKER (2013, p. 34); em contraste, Kroker cita também o artista Mara: "How many people are doing mask and they are for example not African artist or whatever not every mask is from Africa - 
O motivo "máscara e retrato" demonstra a transposição das fronteiras culturais na área da questão da identidade africana, tanto em dimensão coletiva como individual. Segundo Belting, a história da máscara está ligada à história cultural do rosto. "E é certo que a máscara foi sempre usada como mídia - meio de comunicação - do rosto”. (BELTING, 2013, p. 13). Em relação à máscara, ele menciona o paradoxo da uniformização e do contraste de rosto e máscara, o que se expressa especialmente no rosto de uma máscara (BELTING, 2013, p. 25) 14 e da sua dialética de expor e ocultar. (BELTING, 2013, p. 13). Na máscara, o rosto transforma-se num rosto simbólico. (BELTING, 2013, p. 25). "Repita-se que, a máscara sobre o rosto e o próprio rosto não estão em contradição, mas sim no contexto que une a natureza à cultura. Como imagens, ambas estáo sujeitas às pressóes inevitáveis que valem para cada representaçáo". (BELTING, 2013, p. 27). A máscara artificial é, conforme Belting, a excarnação do rosto, porque descorpora o portador, "para "representar" outra pessoa". (BELTING, 2013, p. 27). As máscaras tornam-se, de acordo com Caillois ([1958], p. 97), "ferramentas da metamorfose". Belting opina que todo o culto de máscaras é o resultado do culto de mortos, no qual os antepassados já foram representados na imagem de máscara em culturas pré-históricas. ${ }^{15}$ Por isso, as máscaras têm de ser consideradas sempre em contexto com os costumes de máscaras, como danças rituais, por exemplo. Recorrendo a Robert F. Thompson, Belting remete para a semelhança de máscaras africanas com o rosto de possuídos que se encontram em transe e cujos corpos são considerados como que ocupados por outros seres, os quais usam o corpo hospedeiro como uma espécie de máscara. (BELTING, 2013, p.53).

Por trás das máscaras aparecem espíritos no mundo dos homens que vivem atualmente para lhes comunicar determinadas mensagens, advertências e

mask exist everywhere. (MARA, 2009, p. V.I.6)”. (KROKER, 2013, p. 39).

${ }^{14}$ Lê-se em Belting, também: "A distância do corpo desempenha um papel em nosso conceito de imagem, porque este atribui a figuratividade só à máscara e náo se apercebe das imagens que se produzem na cara". (BELTING, 2013, p. 26) E ainda: "Podemos transformar as nossas caras a cada momento em máscaras e fechá-las (as caras). [...] Já só por isso, a cara e a máscara não se deixam reduzir a uma contradição". (BELTING, 2013, p. 26).

${ }^{15}$ Em Belting (2013, p. 46), afirma-se sobre isso: "Já na cultura da jovem Idade da Pedra do Médio Oriente por volta do ano 7000 antes de Cristo se relatava a invençấo epocal da máscara." E mais: "Milénios mais tarde, as máscaras voltaram outra vez na múmia egípcia, onde unicamente o lugar da cara era marcado visualmente, enquanto que o resto do corpo desparecia envolto em ligaduras". (BELTING, 2013, p. 47). Belting remete para as caveiras com camadas de cal e barro do Neolítico, encontradas também no Médio Oriente, em cujas órbitas tinham sido inseridas conchas. Aqui, a máscara é a própria cara retrabalhada. (BELTING, 2013, p. 47f.). "A cara era trocada por uma máscara, quando a morte a tinha destruído". (BELTING, 2013, p. 48f.) E mais: "Supóe-se que a máscara era entendida como uma imagem da cara que se pretendia restabelecer na cara sustituída". (BELTING, 2013, p. 49). Em outra passagem, encontra-se em Belting (2013, p. 49): "A máscara é a nova cara." 
pedidos do mundo dos espíritos. Os portadores das máscaras tornam-se ferramentas dos espíritos, propagadores de suas mensagens. Deste modo as máscaras constituem o límite entre as dimensóes visível e invisível da realidade. (KIMMERLE, 2008, p. 37).

As máscaras africanas têm de ser entendidas no contexto do culto dos antepassados. Os diferentes tipos de máscaras africanas representam, segundo Franz Kramer, experiências religiosas e a respetiva realidade social numa determinada zona geográfica. (BELTING, 2013, p. 53). No entanto, com respeito a máscaras, pode observar-se também nos índios Nootka, por exemplo, o fenômeno dos retratos:

Por isso, o rosto como documento e lembrança, enquanto base da criação do retrato europeu [...], também está comprovada na área de máscaras. Contudo, ao contrário do retrato europeu, a maioria das máscaras não eram objetos de contemplação, mas sim meios de transformação e requisitos de um culto. (BELTING, 2013, p. 54f).

De acordo com Belting, os europeus, em vez da máscara, desenvolveram o retrato. (BELTING, 2013, p. 17). Com isso, ele associa o retrato inequivocadamente à cultura ocidental: "A cultura europeia inventou no retrato moderno uma máscara ímpar na comparação cultural. Os retratos transformam o rosto que representam inevitavelmente numa máscara que sempre mantém uma distância ao rosto autêntico, porque a substitui". (BELTING, 2013, p. 28). ${ }^{16}$

\footnotetext{
${ }^{16}$ E mais: "O que eram máscaras nas culturas antigas, tornou-se retratos na Modernidade europeia". (BELTING, 2013, p. 28). Além disso adverte que a máscara, na Europa, perdeu já cedo a importância e que se tornou importante na antiguidade no teatro como secularização do culto de máscaras na forma da máscara de dramatizaçáo. (BELTING, 2013, p. 45). Mbembe relaciona a máscara numa maneira específica também ainda hoje com a África. "Quant à la dimension polémique du terme, elle découle précisément de l'étrange puissance que porte le nom "Afrique" et la terrible ambiguité que recèle le mot, à la manière du masque. On le sait, l'une des fonctions du masque est, toujours, de cacher un visage en le doublant - le pouvoir de double, au croisement de l'être et de l'apparence. L'autre fonction est de permettre à celui qui a masquede voir les autres tout en n'étant pas vu; de voir le monde à la manière d'une ombre cachée en dessous de la surface des choses. Mais, si dans le masque se croisent l'être et l'apparence, il est vrai aussi que dans l'impossibilité de voir le visage que cache le masque - cette minuscule béance - le masque toujours finit par s'autodénoncer comme masque. Car, chaque fois que l'on convoque ce nom, l'on revêt automatiquemente chaque corps singulier d'une multitude d'étoffes opaques". Em: MBEMBE, Achille. Critique de la raison nègre. Paris: La Découverte, 2013, p. 82.
} 
Em termos de questóes sobre a identidade africana, a transculturalidade apresenta-se na arte africana contemporânea frequentemente na combinação de elementos ocidentais e africanos, aqui no que diz respeito aos motivos "retrato e máscara", em processos da encenação por exemplo, mediante estilos de vestuário e estranhamento, fenômenos de reciclagem e jogo com posturas de recepção etc. Nisto, a máscara perde cada vez mais seu caráter cultural simbólico e se torna um puro curinga, como observa corretamente o artista Brendan Fernandes, proveniente do Quênia e residente no Canadá.

The neon masks [...] came out of my time as a flaneur on Canal Street in New York City. I watched vendors selling African masks and heard that they were carving them in storage units outside the city. It made me think about the loss of cultural traditions - what happened to the ceremonial purpose and what the masks once meant - and how the masks become just placeholders, like signs. (MCCLUSKY; MASSAQUOI, 2015, p. 30). ${ }^{17}$

Mas também os carateres vazios relacionados com tradiçôes africanas vividas encenam um diálogo intercultural. $\mathrm{O}$ motivo central da máscara que revolucionou a arte europeia da modernidade - a qual revela uma vista exótica ao estranho - e que representa a base do estranhamento dos rostos femininos do quadro introdutor do cubismo "Les Demoiselles" (1907), de Pablo Picasso, ${ }^{18}$ está unido ao diálogo entre a Europa e a África. A arte africana entende-se no sentido do chamado "primitivismo". McClusky remete, dessa maneira, a um "creative misunderstanding". (MCCLUSKY; MASSAQUOI, 2015, p. 83). Ainda nos anos de 2012 a 2014, o artista afroamericano William Villalongo faz alusão ao quadro de Picasso com as suas colagens de fotografias de europeus e americanos despidos, imprimidas em catálogos de casas de leiláo, cujos rostos ele oculta, com grandes ilustrações de máscaras africanas. " $[\mathrm{N}]$ o African mask would ever been worn by a naked woman any traditional masquerader would be horrified by the sight. [...] William Villalongo's series of Artifacts offers a contemporary echo of this culture

\footnotetext{
${ }^{17} \mathrm{Na}$ obra de arte de Fernandes, "Neo Primitivism" (2007-2014), são apresentadas, nas paredes, máscaras falsas com animais selvagens falsos, numa sala printada em verde de safari com silhuetas brancas de comprimentos diferentes e que parecem gráficos em grupos de lanças dispostas paralelamente. (MCCLUSKY; MASSAQUOI, 2015, p. 30).

${ }^{18}$ Por ocasiăo da exposição de Picasso and Africa 2006, em Joanesburgo, debateu-se muito controversamente a importância da arte africana para Picasso. Grill menciona uma "controversa de Picasso". Comp. GRILL, Bartholomäus. Wie die Wilden: Anmerkungen zur immergleichen Wahrnehmung Afrikas und zur Entstehungsgeschichte dieser Ausstellung. Em: KITTELMANN, Udo; OKEKE-AGULU, Chika; SCHMITZ, Britta (Ed.). Who knows tomorrow. Köln: Walther König, 2010, p. 49.
} 
shock”. (MCCLUSKY; MASSAQUOI, 2015, p. 78). ${ }^{19}$ As máscaras eram, conforme Belting, o objeto preferido da apropriação colonial. ${ }^{20}$ Por isso, esse motivo artístico é de importância particularmente excepcional para o debate artístico na arte africana e afrodiaspórica, sobretudo também em termos de identidade africana, quer pessoal, quer coletiva.

\section{Identidade Híbrida. Máscara e Retrato em Edson Chagas e Kehinde Wiley}

A fotografia do angolano Edson Chagas (nasc. 1977), na sua série "Tipo Passe" (2012-2014), trata de maneira perspicaz do tema "máscara/retrato". Ele apresenta fotografias do mesmo tamanho e do mesmo tipo, em formato de 100 x 80 centímetros, como busto em face, que fazem lembrar as fotografias "Tipo passe”. Os corpos e as caras estão voltados para a frente, somente o corpo, por vezes, ao contrário da máscara, dá a impressão de estar voltado ligeiramente para o lado. A maioria das fotografias "Tipo passe" mostra uma pessoa do sexo masculino vestida com terno e camisa, na maioria dos casos com gravata ou laço, e somente uma mulher. A maior parte dos ternos são escuros; as cores das camisas - às vezes brancas, às vezes riscadas em várias cores - e as cores das gravatas e laços - de azul claro unicolor, vermelho ou castanho e com diferentes padróes de várias cores - variam de foto para foto. Uma pessoa está vestida com uma gabardina clara. Só poucos dos homens não trazem casaco vestido por cima da camisa; um homem sobressai com uma camisa com um padrão que dá a impressão de ser africano. A única mulher, Diana S. Sakulombo, está vestida - inspirada pela Europa - com um blazer escuro e uma blusa branca de gola alta, com um precioso broche no meio, abaixo da gola. Em lugar do rosto, mostram-se máscaras africanas provenientes de uma coleção privada. A maioria das mesmas são em madeira de formas e pinturas muito diferentes e tapam todo o rosto das pessoas ilustradas. O diálogo transcultural tem lugar através do objeto de culto africano, ou seja, a máscara, tanto na forma como no conteúdo, pela combinação do gênero de fotografia de retrato - aqui, fotografia de passaporte - e do motivo do homem de negócios que, devido ao

\footnotetext{
${ }^{19} \mathrm{~A}$ autora também adverte que as máscaras, na África, não eram usadas por mulheres em contextos rituais. (MCCLUSKY; MASSAQUOI, 2015, p. 80) Além disso, enfatiza: "He could also explain that masks were not to be bought and sold; instead, they were intended to initiate visitations from beings who would emerge from the forests to contribute their wisdom in times of confusion". (MCCLUSKY; MASSAQUOI, 2015, p. 80).

${ }^{20}$ Em Belting, lê-se sobre isso: "A estranheza da máscara que fascinava por ser exótica foi o motivo para a sua apropriação colonial na Modernidade. No entendimento ocidental da cara, a máscara era o Outro por excelência e era vista somente como mentira e engano". (BELTING, 2013, p. 55).
} 
seu modo de vestir, dá, geralmente, a impressão de uma pessoa de sucesso e bem estabelecida. De acordo com a função de uma fotografia tipo passe, que serve para identificação individual no âmbito da pertinência a um Estado à base de diversas nacionalidades, cada fotografia porta um nome pessoal. ${ }^{21}$ Nos nomes, sobressai uma combinação de primeiro nome, que dá uma impressão europeia, com um sobrenome africano. ${ }^{22}$ Os nomes escolhidos remetem para antigas potências coloniais, como Inglaterra, França e Portugal. Os sobrenomes das pessoas fotografadas como, por exemplo, Makélélé, Bomboko e Mbayo, são geralmente africanos.

Ao tema da máscara africana estão associadas questóes de uma identidade africana e étnica que transcendem referências a Estados nacionais, as quais, observadas historicamente, têm por base os direitos coloniais de possessão e a repartição artificial de territórios africanos. Já o gênero de retrato e os rostos sustituídos por máscaras simbolizam o discurso intercultural, em nível midiático. A combinação híbrida de diferentes elementos culturais repete-se nas cores, formas, padróes e estruturas. Com respeito à questão da identidade pessoal aludida nessa obra de arte pelo nome, pelo rosto (pela máscara) e pelo vestuário nas fotografias, Chagas evoca um conceito de uma hibrididade cultural de identidade que contém tanto uma catividade nas culturas pré- e pós/coloniais da África como culturas ocidentais e suas formas intermédias híbridas no transcultural - uma concepção de identidade no sentido da opinião filosófica de Appiah de criação permanente, combinação e mudança de elementos da identidade pessoal. Na demonstração visual da hibrididade de identidade, sublinha-se ao mesmo tempo uma confrontação crítica com a matéria. Como se unem os diferentes elementos interculturais, no retratado? Quais são as dominâncias que se tornam visíveis? Pode-se pensar o posicionamento da máscara africana em lugar do rosto, por exemplo, como favorização de uma orientação étnica ou de culto religioso na construção de identidade? Que conclusóes podem ser tiradas do exposto, com respeito à questão de uma identidade pessoal, étnica, nacional e/ou africana e global? As obras de arte não respondem a essas perguntas, inequivocadamente, mas convidam a refletir.

${ }^{21}$ Os nomes são: Marcel D. Traoré, Fernando L. Makélélé, Thierry H. Bomboko, Patrice J. Ndong, Cheick F. Ouattara, Pablo P. Mbela, Diana S. Sakulombo, Jean P. Mbayo, Salvador D. Kimbangu, Leroy M. Futa, Diogo K. Puenha, Emmanuel C. Bofala, entre outros.

22 Marcel, Jean e Patrice são nomes franceses, Salvador, Emmanuel e Pablo, portugueses, ou seja, espanhóis, e Leroy e Thierry, ingleses. 
Na série fotográfica OIKONOMOS (2011-2012), Chagas mostra retratos de meias figuras quadradas, ${ }^{23}$ coloridas, voltadas para a frente e com a cabeça enfiada numa sacola ou bolsa de compras, muitas vezes meio torcidas e, na sua maioria, em plástico ou tecido. Essas sacolas são estampadas sobre fundos geralmente brancos, às vezes também verde-escuros, azuis ou pretos, com letras estrangeiras em preto ou coloridas e/ou imagens que ostentam publicidade de produtos asiáticos, europeus e americanos. O protagonista está vestido com uma camisa social branca, a qual remete para o estilo de vestir ocidental e acentuadamente neutro. Com o rosto tapado pelas sacolas de compras, que assumem a função de uma máscara, mas também reminiscências de rostos vendados e tapados, os retratos masculinos demonstram a perda da face e, com isso, da identidade pessoal; esta é substituída pela identidade de um consumidor de produtos globais. "Este [o rosto] é mais do que uma parte do corpo, porque atua como substituto ou pars pro toto do corpo inteiro". (BELTING, 2013, p. 26). Ela torna-se substituta da pessoa com a sua respetiva identidade específica. A importância da face não é reduzida pela encenação fotográfica de sua negação, porque a sua falta levanta novamente a questão da identidade africana, sob condiçóes pós-coloniais num mundo globalizado: ela apresenta-se frequentemente figurada de forma exagerada. A máscara incorporada em contextos rituais perde a sua referência à cultura tradicional africana e inscreve-se na cultura de consumo global. Os ritos religioso-míticos que estruturam a vida quotidiana são substituídos por costumes de consumo, os quais desembocam num culto de consumo em forma de mistificação do mesmo. A dimensão analítico-crítica das obras de arte, que se manifesta, vai mais além do contexto relacionado com a África e deixa-se ler de forma generalizada, porque as fotografias, devido à falta de elementos africanos específicos e ao recurso a objetos com símbolos de todo o mundo, podem estar igualmente relacionadas com outros âmbitos culturais. Por isso, a infiltração transcultural de elementos visuais torna-se visível de forma aumentada. Ao mesmo tempo, encena-se e desmascara-se visualmente o direito hegemonial da economia global e tematiza-se a questáo com respeito ao contexto de economia e identidade, e uma possível homogenização de identidades, em função do processo econômico global.

Os retratos do artista afro-americano Kehinde Wiley (nasc. 1977) marcam um outro tipo de tratamento do tema de retrato. Para ele, é primariamente importante uma vista desmascaradora da encenação de

\footnotetext{
${ }^{23}$ As fotografias são de formato $60 \times 60,80 \times 80$ ou $105,4 \times 105,4 \mathrm{~cm}$.
} 
poder mediante composição, gestualidade, mímica etc., conforme a tradição europeia do retrato de soberanos e a autorização de homens morenos, até agora marginalizados, mediante apresentação visual frequentemente associada a elementos gráfico-simbólicos parecidos a ornamentos e tecidos, que, tanto geográfica como historicamente, dão a impressão de culturas "estranhas". Ao mesmo tempo, na sua arte, pode-se observar também um gesto crítico/irônico de questionamento e exposição do artístico-histórico reportório da encenação do poder, particularmente com respeito ao conceito da virilidade hegemonial. Em Kehinde Wiley, destaca-se a hibrididade da linguagem visual: ele apresenta, na sua arte, sobretudo pessoas de origem afro-americana em poses que lembram as obras de antigos mestres, como Ticiano, Rubens, van Dyck, Ingres e David. Afro-americanos, africanos, afro-brasileiros, índios, etíopes e árabes são apresentados em poses heróicas, por exemplo, desfavorecidos da sociedade, ${ }^{24}$ mas também artistas pop e hip hop, como Michael Jackson e Ice-T. Para isso, Wiley aproveita a linguagem visual clássica que atribui importância social a pessoas poderosas e com muita influência e as documenta artistica e historicamente, refletindo assim, na sua arte, o diálogo entre arte e poder. Dirige sua simpatia às pessoas discretas da sociedade, que, nas suas pinturas, se tornam heróis e são apresentadas em vestuário quotidiano, como, por exemplo, roupas esportivas ou sweatshirt com capuz e chapéu ou boné de basebol. Em geral, os fundos estão enfeitados com padrôes e ornamentos que proporcionam reminiscências de desenho têxtil africano, arquitetura islâmica, rococo francês etc. As tradicionais molduras de ouro, o precioso desenho e a escolha do material tinta a óleo reforçam a impressão de muito valor. Para Wiley, é importante revelar na sua arte igualmente aspetos do colonialismo e abrir seu debate, quanto à França atual, em relação à história colonial; as suas representaçóes de tunísios e marroquinos, por exemplo, manifestam esse relacionamento com a situação pós-colonial. O homem subalterno exprime-se na encenaçáo artística de Wiley, que se apropria da linguagem visual do antigo colonizador. "[O]ne could argue that this contest for power had also become interwoven with competing victimhoods, victimhood in a postcolonial context being seen as moral grounds for recuperating postcolonial leadership and political, social and sexual power". (BELTING, 2013, p. 26; REDDOCK, 2004, p. xxi). Isso pode ser interpretado como ato subversivo, como mimetismo, no sentido de Bhabha (2004, p. 122f).

\footnotetext{
${ }^{24}$ Wiley contacta pessoas na rua. Tira-lhes fotografias para pintá-las mais tarde, por exemplo, no Brasil,
} Marrocos e Tunísia. 
Mimicry is, thus the sign of a double articulation; a complex strategy of reform, regulation and discipline, which "appropriates" the Other as it visualizes power. Mimicry is also the sign of the inappropriate, however, a difference or recalcitrance which coheres the dominant strategic function of colonial power, intensifies surveillance, and poses an immanent threat to both "normalized" knowledges and disciplinary powers.

O significado da experiência estranha híbrida é invertido em estratégias de autorização no sentido pós-colonial. O third space, que se abre nas concepçóes e obras de arte dos artistas descritos, mostra maneiras de aparência muito diferentes. Em Wiley, o ponto central é o jogo intervisual de referências da história da arte para o debate com códigos simbólicos da representação do poder em referências pós-coloniais que devem ser entendidos como estreitamente vinculados a concepçóes de masculinidade. $\mathrm{O}$ contexto de identidade e transculturalidade é visualizado e refletido nas obras de Chagas e Wiley, com diversas estratégias estéticas.

\section{Crossing Borders. Identidade, Máscara e Retrato em Yinka Shonibare e Romuald Hazoumè}

O artista afrobritânico Yinka Shonibare (nasc. 1962) trata, com respeito ao tema analisado, em sua série fotográfica composta por cinco fotografias - "Diary of a Victorian Dandy" (1998) 25, o motivo de autorretrato como encenação da época victoriana, na qual um Dandy moreno está no centro do acontecimento, cujo decurso do dia é reproduzido em estações. Shonibare recorre ainda a tradiçôes visuais, e a base de suas fotografias é constituída especialmente das obras satíricas de William Hogarth. A decadência, a preguiça, a frivolidade e as autoencenaçoos, tanto estéticas como sociais, são expostas e, adicionalmente, como em Wiley, são invertidas irônicocriticamente, mediante inversão dos papéis de pretos e brancos. Shonibare mesmo representa o Dandy moreno, de modo que se evoca igualmente o tema de "autorretrato", ou seja, o "autorretrato do artista", com o qual se inicia indiretamente um diálogo intervisual com autorretratos de outros artistas. O Dandy negro, ou seja, o artista, está sempre no centro da composição,

\footnotetext{
${ }^{25}$ A série do ano de 1998 contém as fotografias de "Diary of a Victorian Dandy: 11.00 hours" "Diary of a Victorian Dandy: 14.00 hours", "Diary of a Victorian Dandy: 17.00 hours", "Diary of a Victorian Dandy: 19.00 hours" and "Diary of a Victorian Dandy: 03.00 hours". As fotos são de formato 183 x $228,6 \mathrm{~cm}$ e pertencem à Gordon Schachat Collection, da África do Sul.
} 
usando na maioria o método da seção áurea, o que se reflete também na concentração da atenção dos demais presentes e encena o artista negro como importante. Com isso, Shonibare faz alusão ao mesmo tempo à necessidade da autoencenação do artista, mediante alteridade exótica no culture game $e^{26}$ no mercado de arte. Com a encenação do autorretrato como cena do gênero, esse aspeto não está explicitamente no centro, porém, está muito presente na recepção das fotografias. Na sua vídeoinstalação "Um baile de máscaras", na qual recorre aos meios cinematográficos de Jean-Luc Godard e de Alain Resnais e na série fotográfica do mesmo nome (2004-2005), Shonibare trata o tema da máscara, mostrando máscaras e trajes que dão a impressão de ser africanos, num baile de máscaras de inspiração veneziana, produzidos pelo conhecido método wax print, com tecidos holandeses fabricados na Ásia com padróes africanos, ${ }^{27}$ de sorte que se produz um contraste híbrido entre padrão e estilos de traje e máscara. Os tecidos utilizados simbolizam e problematizam, já em nível do material, o contexto da transculturalidade e identidade, em termos de uma pretensa autenticidade. As culturas são concebidas, desde sempre, como formações híbridas. A matéria da vídeoinstalação e da série fotográfica trata a ópera de Guiseppe Verdi do mesmo nome, do ano de 1859, que póe em cena o assassinato do rei sueco Gustavo III, num baile de máscaras, em Estocolmo, no ano de 1792. No vídeo, o acontecimento é mostrado repetidamente, numa linha sem fim. ${ }^{28} \mathrm{O}$ rei sueco alheia-se ironicamente e é representado por uma

${ }^{26}$ Comp. adicionalmente o capítulo "Double Dutch and the Culture Game”, in: OGUIBE, Olu. The Culture Game. Minneapolis, London: University of Minnesota Press, 2004. p. 33-44.

${ }^{27} \mathrm{O}$ artista utiliza esse material pela primeira vez, em 1994, na sua série de quadros com o título "Double Dutch", os quais são apresentados sobre um fundo cor de rosa e, em 1997, em "Deep Blue", para a qual escolhe uma parede em azul profundo. "Shonibare's Double Dutch, understated and misunderstood as it is, must nevertheless stand as one of the most important works of cultural contestation in the late twentieth century because, far more than any other work in contemporary British art, it succeeded in outwitting and subverting the desires and machinations of the culture of difference that is at the heart of the global contemorary-art machine". (OGUIBE, 2004. p. 40). Shonibare encontrou o tecido "africano" em Brixton, no Sul de Londres. "The signifier that would denote and inscribe his Otherness is, after all, entirely British and has little or nothing to do with Africa or Elsewhere. (OGUIBE, 2004, p. 40). O nome "Double Dutch" não recorre somente ao método holandês wax print, mas também a um jogo de salto à corda do mesmo nome e a um jogo linguístico no qual são substituídas determinadas letras das palavras; por exemplo. "As a metaphor, therefore, Shonibare's title was a sleight of hand, referring as it does to cultural acrobatics in which the players are masters of the game. In choosing his title, Shonibare indicated his readiness to engage the culture game of the Western metropolis and to bring to it the necessary mental and performative sophistication". (OGUIBE, 2004, p. 41).

${ }^{28}$ É que a série fotográfica do mesmo nome termina com a cena do monarca assassinado deitado no chão, mas poderia ser encenada também circularmente, pendurando-se várias séries em círculo, ao mesmo tempo. 
mulher, nas obras, para inverter as condiçóes dos sexos. A troca de papéis encenada em Shonibare pode ser interpretada como jogo irônico de mostrar e esconder a pessoa, o sexo e o estado social, e como levantamento da questão do idêntico na formação de identidade - também em termos de identidade artística própria - no sentido de uma metáfora de jogos de poder.

Também o artista proveniente do Benim, Romuald Hazoumè ${ }^{29}$ (nasc. 1962), confronta-se, em seus masques bidons, intensamente com o motivo máscara. O material que emprega para confecionar suas máscaras, ou seja, galóes plásticos de gasolina, está em contraste com os materiais tradicionalmente usados para máscaras africanas; desde aproximadamente 1990, ele confeciona sempre novas e diferentes "máscaras de galáo", as quais, entre outros elementos, refletem o fetichismo de objetos do ponto de vista ocidental e o aproveitamento da cultura africana e sua possível liquidação. Simultaneamente, esse procedimento artístico da transformação simboliza o talento de improvisação dos africanos na luta quotidiana pela subsistência. (WEBER, 2012, p. 110). Os galóes de poliéster representam, por um lado, o estilo de vida ocidental e sua mobilidade e, para além disso, a importância do petróleo para as economias africana e internacional e os efeitos para o poder associados à sua exploração, transformação e comércio, os quais se repercutem igualmente, na vida quotidiana, tanto da população africana como da população mundial. Ao contrário da série fotográfica OIKONOMOS, de Chagas, os galóes de plástico foram aqui transformados claramente em máscaras africanas, individualizadas com perucas, joias etc. $\mathrm{O}$ processo de uma incorporação e adoção "africana" na formação artística das máscaras deve ser entendido igualmente como procedimento híbrido transcultural, contudo, na arte de objetos de Hazoumè fica existindo nitidamente a referência africana comparável ao uso das máscaras africanas originais na série "Tipo passe”, de Chagas. No entanto, o artista Hazoumè acentua ironicamente, numa entrevista, que o motivo máscara ${ }^{30}$ é gerado somente do ponto de vista ocidental, porque ele próprio nunca tivera a intenção de confecionar máscaras. Esse jogo irônico - particularmente com os recipientes ocidentais - é caraterístico para a criação artística de Hazoumè e manifesta o caráter metadiscursivo de sua arte, a qual inclui e reflete artisticamente desde sempre a vista pós-exótica e um interesse de aproveitamento hegemonial. Essas obras de arte de Hazoumè têm como

\footnotetext{
${ }^{29}$ Para informaçáo mais detalhada sobre o artista Hazoumè, ver a palestra de Daniela Roth (2009). Ver também: Roth (2013).

${ }^{30}$ Belting (2013, p. 56) acentua: "Nas línguas africanas nâo existe nenhum lexema próprio para máscara, porque esta era a própria cara que ostentava."
} 
base a concepção de uma identidade híbrida que, com a utilização da estética da reciclagem ou da transformaçáo, tematiza, ironiza e reflete particularmente a questão dos padróes dados e de estereótipos.

$\mathrm{Na}$ instalação La Bouche du Roi, criada de 1997 a 2005 e exposta em 2007, no British Museum de Londres, por ocasião do $200^{\circ}$ aniversário da proibição da escravatura, Hazoumè trata artisticamente o tema escravatura. 304 galóes de gasolina transformados em máscaras formam o casco de um navio negreiro; a relação das máscaras individualizadas com a religião é manifestada mediante objetos de culto posicionados na proa do navio. $\mathrm{O}$ aperto que havia no navio é encenado através da proximidade das máscaras. A espingarda simboliza a violência usada. As vasilhas partidas instaladas são símbolo das pessoas que morreram durante a travessia, as pequenas máscaras evocam as mulheres e crianças. $\mathrm{O}$ transporte de escravos do Benim tinha seu ponto de partida na foz do rio Couffo. Os escravos eram trocados pelos soberanos negros por armas, tabaco, álcool, espelhos, pérolas e tecidos. Hazoumè critica essa cooperação do rei negro, simbolizado pela máscara preta no casco do navio, com os traficantes brancos de escravos. A máscara amarela lembra o colonizador francês. Ambas são as culpadas da miséria humana associada ao tráfico de escravos e suas consequências, exprimida pelo prato da balança como parte do corpo do navio. Os trabalhos de Hazoumè estabelecem uma ligação entre a escravatura histórica e os movimentos de refugiados atuais, ${ }^{31}$ que, segundo ele, exprimem uma escravidão moderna. Também hoje a elite negra faz parte dos beneficiários das situaçôes políticas e econômicas, as quais levam à fuga de refugiados em massa. As conotaçóes políticas das obras de arte de Hazoumè manifestam, à sua maneira, o potencial de emancipação que a arte encerra, igualmente no aspeto sociopolítico, pela encenação artística da problemática da identidade africana, em contextos de poder interculturais. Em suas estratégias artísticas de tratamento conceptual e visual da temática "identidade e transculturalidade", Shonibare e Hazoumè recorrem ambos, de igual modo, a um jogo metarreflexivo e irônico, manifestado nos motivos máscara e retrato.

\section{RESUMo}

A concepção filosófica de Appiah revela-se, na análise das obras de arte, como o instrumentário adequado para compreensão da arte contemporânea

\footnotetext{
${ }^{31}$ Nesse sentido, é de importância sobretudo a instalação "Dream” (2007), mostrada na Documenta 12.
} 
africana sobre a temática "identidade e transculturalidade", no que concerne aos motivos "retrato e máscara". As obras de arte apresentadas evidenciam o processo narrativo e combinatório da formação de identidade, nas mídias visuais fotografia, cinematografia, arte de objetos e pintura, mediante estratégias visuais no metanível, de modo que, na arte, é possível conceber uma narração visual com respeito à temática da identidade. "It's about elucidating how identity can function in the contemporary world. There is known history and then there is the reinterpretation of that history that leads to new ways of approaching selfhood in culture." ${ }^{2}$ As "landscape of blackness" e "whiteness" e as questóes pós-coloniais continuam sendo aspetos essenciais. Também no visual, deve-se partir de uma sucessão, quer na configuração e percepçáa pelo olhar sintetizante, que percorre uma obra de arte e todos os seus respectivos componentes, quer no pensamento evocado sobre a obra de arte, tanto no processo de criação como no processo de recepção, no qual de maneira interpretativa se cria um contexto narrativo que focaliza aqui o aspeto da identidade e transculturalidade. No entanto, pode existir ao mesmo tempo, eventualmente, um entendimento direto da obra de arte e uma grandiosidade estética arrasadora. As obras de arte refletem o debate crítico da formação de identidade, no contexto africano global, com a utilização propositada de meios visuais de criação que recorrem a espaços culturais distintamente imaginados, como, por exemplo, momentos que se percebem como momentos africanos em forma de tipos de artefato, padróes e estruturas, cores, ou seja, combinaçôes de cores e elementos atribuídos à cultura ocidental como gêneros, temas, materiais etc., hibridamente combinados uns com os outros, o que, frequentemente, está associado à estilização e à estereotipia, não apenas na produção, como na recepção. Observando-se diferentes obras de arte em comparação, o resultado é, por um lado, uma composição de contrastes e, por outro lado, uma harmonia e coexistência (quase) indiferenciável, por vezes com uma impressão misteriosa, criando algo novo.

Notável é que a vista do ex-descobridor e ex-colonizador que contempla algo estranho exótico, nas obras de arte contemporâneas sobre o tema máscara/ retrato, em geral se inverte. Também o ex-descoberto e ex-colonizado contempla o outro da cultura estranha de maneira exotizadora. "The imagining of the european explorer by the African carver represents a kind of ironic inversion of the depiction of the exotic "other". Here the gaze is reverted back into the

\footnotetext{
${ }^{32}$ A artista Saya Woolfalk, em Mcclusky e Massaquoi (2015, p. 52).
} 
european as something foreign and alien." ${ }^{\text {"33 }}$ Esse tipo de contemplação entra na concepção, realização e recepção de obras de arte de maneira diferente. Por um lado, são utilizados soberanamente os meios de criação europeus, tais como gêneros tradicionais, temas, procedimentos de composição e, por outro, ironizados e invertidos no sentido de uma estratégia de autorização. $\mathrm{O}$ modo de tratar o tema "retrato e máscara", nas obras de arte, revela uma tendência metarreflexiva em aspeto estético, artístico-teórico e artístico-histórico e no projeto artístico do debate intelectual de temas histórico-políticos. A arte visual mostra-se como meio de debate visual com questôes da identidade, num mundo de encontro da diversidade cultural com implicaçóes político-sociais. Ela reflete também, claramente, em função de sua função memorial, o processo de formação e negociação de identidades individuais e coletivas concernentes à África e à diáspora africana, em contexto global.

RAINSBOROUGH, Marita. Crossing borders: the philosophy of identity and transculturality in contemporary African art. Trans/Form/Açāo, Marília, v. 39, p. 133-154, 2016. Edição Especial.

\begin{abstract}
The issue of identity is at the heart of Kwame Appiah's philosophy. Taking Mill's concept of liberty as his starting point, he views the development of a personal identity in the sense of a particular individuality as an ongoing task - as an individual project. In this context, life plans should not be understood as strictly linear but rather as disparate and continuously changing. Identity is thus not something which is fixed and closed but rather similar to a mosaic, consisting of various elements which are always shifting - a hybrid entity. The construction of identity includes the telling of life stories, both of a collective and of a personal nature. When doing so, each element may refer to diverse, transcultural experiences in keeping with the history of the collective and the life story of the individual. Transculturality is thus of significance not only for collective identities but also always on the level of personal identity. The African philosopher Achille Mbembe speaks of human nomadism and the associated cultural immersion and dispersion, which can be interpreted as transcultural processes. These processes of identity formation are reflected in the transculturality of contemporary African art. Selected works of artists Edson Chargas, Kehinde Wiley, Yinka Shonibare and Romuald Hazoumè will be presented as examples of this.
\end{abstract}

KEYWORDS: Personal and collective identity. Transculturality. Contemporary African art. African diaspora. The culture game.

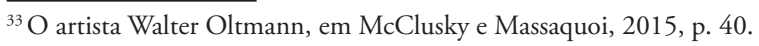




\section{REFERÊNCIAS}

APPIAH, K. A. The Illusions of Race. In: EZE, E. C. (Ed.): African Philosophy: An Anthology. Malden; Oxford; Carlton: Blackwell Publishers, 1998. p. 275-290.

. African Identities. In: BOXILL, B.(Ed.): Race and Racism. Oxford; New York: Oxford University Press, 2001. p. 371-382.

. The Ethics of Identity. Princeton: Princeton University Press, 2007a.

. Cosmopolitanism: Ethics in a world of strangers. London; New York; Dublin: Penguin Books, 2007b.

BELTING, H. Faces: Eine Geschichte des Gesichts. München: C. H. Beck, 2013.

BHABHA, H. K. The Location of Culture. London; New York: Routledge, 2004.

CAILLOIS, R. Die Spiele und die Menschen: Maske und Rausch. München, Wien: Albert Langen; Georg Müller, o. J., [1958].

DHOUIB, S. Zur transkulturalität der Menschenrechte. Em: DHOUIB, S.; JÜRGENS, A. (Ed.): Wege in der Philosophie: Geschichte - Wissen - Recht - Transkulturalität. Weilerswist: Velbrück Wissenschaft, 2011. p. 278-296.

; JÜRGENS, A. (Ed.). Wege in der Philosophie: Geschichte - Wissen - Recht Transkulturalität. Weilerswist: Velbrück Wissenschaft, 2011.

ELBERFELD, R. Forschungsperspektive "Interkulturalität": Transformationen der Wissensordnungen in Europa. Em: KONERSMANN, R.; KROIS, J. M.; WESTERKAMP, D. (Ed.). Zeitschrift für Kulturphilosophie, Bd. 2/1, 2008. p. 7-36.

GRILL, B. Wie die Wilden: Anmerkungen zur immergleichen Wahrnehmung Afrikas und zur Entstehungsgeschichte dieser Ausstellung. Em: KITTELMANN, U.; OKEKEAGULU, C.; SCHMITZ, B. (Ed.). Who knows tomorrow. Köln: Walther König, 2010. p. 45-55.

HOBSBAWM, E.; RANGER, T. (Ed.). The Invention of Tradition. Cambridge: Cambridge University Press, 2015.

HÜHN, M. et al. (Ed.). Transkulturalität, Transnationalität, Transstaatlichkeit, Translokalität: Theoretische und empirische Begriffsbestimmungen. Münster; Berlin; London: LIT, 2010.

KIMMERLE, H. Spiegelungen westlichen und afrikanischen Denkens. Nordhausen: Traugott Bautz, 2008.

KITTELMANN, U.; OKEKE-AGULU, C.; SCHMITZ, B. (Ed.). Who knows tomorrow. Köln: Walther König, 2010.

KROKER, M. Weltwärtige Künstler Wege: Künstler im Kontext der Diskurse über zeitgenössische Kunst aus Afrika, afrikanische Diaspora und Globalisierung visueller Kunst. Wien; Berlin: LIT, 2013. 
MBEMBE, A. Afropolitanisme. Africultures. 26 dez. 2005, p. 1 f. Disponível em: <http:// www.africultures.com/php/?nav=article\&no=4248>. Acesso em: 15 fev. 2016.

Critique de la raison nègre. Paris: La Découverte, 2013.

MCCLUSKY, P.; MASSAQUOI, E. D. (Ed.). Disguise: Masks and Global African Art. New Haven; London: Seattle Art Museum; Yale University Press, 2015.

OGUIBE, O. The Culture Game. Minneapolis; London: University of Minnesota Press, 2004.

REDDOCK, R. E. Interrogating Caribbean Masculinities: an Introduction. Em: REDDOCK, R. E. (Ed.). Interrogating Caribbean Masculinities: Theoretical and Empirical analyses. Jamaika; Barbados; Trinidad; Tobago: University of the West Indies Press, 2004. p. XIII-XXXIV.

ROTH, D. Romuald Hazoumé: ein Are der Yoruba. 2009. Disponível em: <http://www. about-africa.de/kamerun-nigeria/114-romuald-hazoume-are-yoruba>. Acesso em: 15 fev. 2016.

. Romuald Hazoumè: Mister Kanister und die orale Postmoderne. München: Fink, 2013.

RUTHERFORD, J. The Third Space: Interview with Homi Bhabha. In: RUTHERFORD, J. (Ed.). Identity, Community, Culture, Difference. London: Lawrence and Wishart, 1990. p. 207-221.

TRIKI, F. Pluralisme Culturel et Transculturalité. Em: KÜHNHARDT, L.; TAKAYAMA, M. (Ed.): Menschenrechte, Kulturen und Gewalt: Ansätze Einer Interkulturellen Ethik. Baden-Baden: Nomos, 2005. p. 323-339.

. Die Transkulturalität der Philosophie: Die Philosophie des Mittelmeerraums. Em: DHOUIB, S.; JÜRGENS, A. (Ed.). Wege in der Philosophie: Geschichte - Wissen - Recht - Transkulturalität. Weilerswist: Velbrück Wissenschaft, 2011. p. 358-369.

WEBER, J. S. Found, Remade, Repurposed, Transformed. In: ARONSON, L.; WEBER, J. S. (Ed.). Environment and Object: Recent African Art. München; London; New York: Del Monico Books; Prestel, 2012. p. 93-116.

WELSCH, W. Was ist Eigentlich Transkulturalität? Em: KIMMICH, D.; SCHAHADAT, S. (Ed.). Kulturen in Bewegung: Beiträge zur Theorie und Praxis der Transkulturalität. Bielefeld: Transcript, 2012. p. 25-40.

Recebido / Received: 03/06/2016 Aprovado / Approved: 06/08/2016 
RAINSBOROUGH, M. 